\title{
Current Applications of Electrotherapeutics in Collagen Healing
}

\author{
Matthew J. Snyder, BS*, Joel A. Wilensky, PhD*, and Joseph D. Fortin, DO**
}

Electrical current flow appears to be integral to the healing of collagen containing tissue, i.e., bone, cartilage, ligaments, tendons and skin. Accordingly, it is reasonable to hypothesize that externally applied electrical fields should be able to enhance healing, especially in conditions that have resisted more standard treatments. Nevertheless, applications of electrotherapeutics is challenging because the precise mechanism of action is unknown and, accordingly, there is an almost unlimited combination of stimulation parameters (e.g., type of waveform, voltage, current, phase, frequency, etc.) that can be applied to a treatment site. Presently, of the three major types of electrical stimulation, i.e., direct, and capacitive and inductive coupling, there is a growing trend toward utilization of the latter because of its efficacy and greater margin of safety. Although the mechanisms of action for enhanced healing of all three types remain elusive there is increasing evidence that electrical stimulation

\section{INTRODUCTION}

The modern approach to utilizing electrotherapeutics to accentuate healing in collagen containing tissue was pioneered by Japanese scientists, Yasuda et al (1) and Fukada and Yasuda et al (2). They demonstrated that bone formation has electromechanical properties, i.e., stress on bone leads to biopotentials that presumably stimulate bone formation (Fig 1).

This finding led to the large and continuing body of basic and clinical research designed to reveal the most efficacious type and amount of externally applied electrical energy for accentuating healing in bone, cartilage, tendon, ligaments and skin, especially in situations in which natural healing has not occurred. Unfortunately, however, the exact mechanism of action of electrotherapeutics is still unknown. Similarly, it is still unclear precisely when

From *Department of Anatomy, Indiana University School of Medicine, Fort Wayne, Indiana and **Spine Technology and Rehabilitation, Fort Wayne, Indiana. Address correspondence: Dr. Joel A. Vilensky, Indiana University School of Medicine, 2101 Coliseum Blvd. E., Fort Wayne, IN 46805. E-mail: vilensk@ipfw.edu exerts its influence via effects at the cellular and/or molecular levels within the tissue. Utilization of electrotherapeutics has been most prevalent in bony injuries resistant to healing, but applications to severe lesions of skin and ligaments, and even to degenerative joint disease seems promising as cartilage has been shown to be more responsive than bone to applied electrical energy. We conclude that there is a clear trend toward greater orthopedic utilization of inductive stimulation and that, despite the lack of definitive guidelines relating specific parameters with specific conditions, electrotherapeutics appears to be a safe and often effective treatment for collagen containing tissues in many cases in which more standard therapies have failed.

Keywords: Electrical stimulation, faradic stimulation, capacitive coupling, inductive coupling, pulsed electromagnetic fields

electrotherapeutics are most beneficial (i.e., why they work in some cases and not in others) or the optimal type and parameter settings for each case (i.e., maximum benefit with minimal risk of deleterious effects). This ambiguity understandably leads to a certain resistance among physicians to use electrotherapeutics.

\section{TYPES OF STIMULATION}

\section{Direct (Faradic) Stimulation}

Direct or Faradic stimulation has been the most commonly used type of electrical stimulation and is the most basic in its application. Electrodes are typically placed externally on the skin near the treatment site or at the site of interest (e.g., implanted electrode) and an electrical potential, often supplied by a battery pack is applied across the electrodes. Direct stimulation is typically divided into several subtypes based on the potential (i.e., voltage) across the electrodes and type of current used. These subcategories include DC, DC interrupted or pulsed, and symmetric/asymmetric timevarying AC (3). The voltages reached within the tissues are typically low ( $<1.5$ volts) although high-voltages (6-200 volts) applied in pulsed currents have also been used successfully (4,5). Lampe (4) suggested that high-voltage pulsed direct current (HVPDC) was much safer to use than 


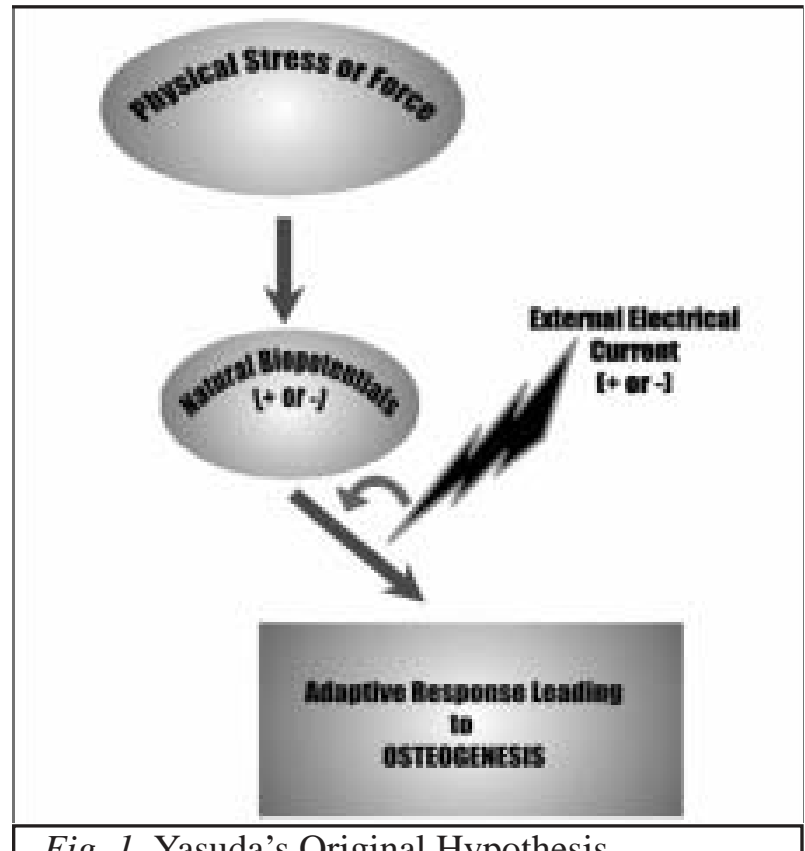

Fig. 1. Yasuda's Original Hypothesis

continuous DC because the current was applied in short bursts rather than continuously. Nevertheless, the currents used in both low- and high-voltage direct stimulation are in the microampere to nanoampere range. In $\mathrm{AC}$ stimulation via external or implantable electrodes, the frequency typically remains below or near $3 \mathrm{kHz}(3)$.

When pulsed current is used, pulse characteristics (duration, rate, and power) are altered to maximize the desired effect (collagen healing) and minimize adverse effects (e.g., overheating the tissue) $(4,6-9)$. Thus, high-voltage applications are typically of short pulse duration whereas lowvoltage applications are of longer pulse duration $(4,5)$.

Variation in electrode size $(5,10)$, placement $(4,5,11-13)$, material type $(3,5,13-17)$, and shape $(5,10)$ also has significant effects on collagen healing. For example, silver electrodes permit higher currents at lower voltages than do other metals. Silver electrodes also release silver ions, which may have an antibacterial effect and are of lower toxicity to mammalian cells than other metals (14). However, Spadero (16) analyzed bone growth around various metallic electrodes and reported that vitallium and platinum were more osteogenic than silver.

\section{Capacitive Coupling Stimulation}

A capacitor is a passive electronic device that stores energy in the form of an electrostatic field. The most basic capaci- tor consists of two electrode plates that are separated by an insulating material. Current applied to a capacitor slowly builds on either side of the insulating material. Clinically, the capacitor exists as two electrode plates that are typically placed on opposite sides of the treatment location (e.g., anterior and posterior surfaces of the forearm in a fracture of the radius/ulna) $(3,18)$. The plates produce a time-varying electrical field as the potential between the electrodes is varied. The local voltage gradients in the tissue between the plates typically equal $1-10 \mathrm{mV} / \mathrm{cm}$, which, in turn, produces miniature local current flows. The field is usually generated by a low power battery pack producing $1-10 \mathrm{~V}$ at frequencies ranging between $20-200 \mathrm{kHz}(3)$.

Numerous parameters exist for controlling capacitive coupling. Many are similar to those of direct stimulation (e.g., pulse characteristics), but with the addition of plate orientation and position characteristics. Although biological effects have been noted to occur when an internal voltage gradient of $0.5-1.5 \mathrm{mV} / \mathrm{cm}$ has been maintained, (3) the high variability in prior use of the controlling parameters greatly increases the difficulty in evaluating the efficacy of capacitive coupling as an electrotherapeutic tool. Further, the recent successes of inductive stimulation have decreased the utilization of capacitive coupling.

\section{Inductive Stimulation (Pulsed Electromagnetic Fields; PEMF)}

Inductive stimulation generates its therapeutic effects by producing both magnetic fields and secondary electrical fields around the treatment site, although it remains questionable as to which is most important $(3,19-23)$. These fields are generated by externally-applied electrical coils overlying the treatment site $(3,5,18,19,23-25)$. The coils, which are most commonly a pair of Helmholtz coils, an electromagnet coil, or a spiral air coil,(23) are usually arranged so that the coil's axis is near the site to be stimulated (e.g., coils overlying an unfused spinal column fracture) $(3,26)$.

Coil design can however be adjusted to better focus on the injured site. Zimmerman et al (27) proposed that butterfly and 4-leaf planar coils have a greater focusing ability compared to typical planar coils (planar refers to the type of electrical field produced, not to the coil itself). They also proposed that slinky coils, which are more three-dimensional, may have even better distribution advantages over planar designs. Essentially, by changing the coil alignment, the three-dimensional distribution of the highest magnetic field intensity can be varied.

The coils can be powered by battery packs worn by the 
patient or house lines for up to 24 hours/day producing time-varying voltages (usually between 10-100V), and magnetic fields of $0.1-50$ Gauss $(3,7,23,28)$ The magnetic field within the treatment area induces small currents in the tissue $(3,5,7,19,23,29,30)$, in particular in the extracellular fluid (21). The local voltage gradients produced by the induced current are usually between $1-10 \mathrm{mV} / \mathrm{cm}$ (3), but can occur outside this range and still have some beneficial effect (31-33). The induced currents are low, but may be large enough to stimulate excitable tissues (i.e., muscle, nerve) although this is not typically seen or desired $(23,34)$.

Pulse characteristics are extremely important in inductive stimulation, with different frequencies believed to be most beneficial for different types of tissues (9,20,24,35-37). However, as yet there is no consensus supporting the use of specific frequencies for specific tissue types. Typically, the frequency is between 2 and $300 \mathrm{~Hz}$ in a complex, asymmetric form $(3,20)$, but some megahertz frequencies are also known to have biological activity (i.e., healing effects) (38). Other pulse characteristics such as amplitude $(7,9,23,28,34,36,37)$ and duration $(9,23,39)$ have also been considered to be pertinent for inducing collagen healing.

PEMF stimulation has becoming increasingly more prevalent partly because it has been recognized that it offers wider latitude in parameter settings relative to minimizing the likelihood of tissue damage. This minimization is partly due to the placement of the coils some distance from the skin (i.e., separated by cast, bandage, towel, etc). PEMFs also do not appear to cause any discomfort during treatment, which may be specifically notable with direct stimulation.

Although most PEMF stimulators are non-invasive, internal focusing "gelectrodes" have been developed that are placed near or within the treatment site to more effectively localize the induced currents. Tiny computer chips within these electrode capsules respond to the magnetic fields to alter waveforms and pulse rates in addition to highly focusing the incoming fields and currents (40). Although this technique has been sparingly used experimentally in neuromuscular applications (e.g., spinal cord injury rehabilitation, intraoperative monitoring, electrodiagnostics) it has yet to be directly applied to clinical orthopedic or rehabilitation conditions presumably because of concern for inducing concentrated currents that could lead to burns.

\section{MECHANISMS}

The key to increasing the utilization of electrotherapeutics clearly resides in attaining a better understanding of the precise mechanism of action. Without this understanding, its application will continue to rely primarily on empirical findings, thereby leading to reluctance to its usage among many physicians.

Although there is a demonstrable relationship between mechanical stress on bone and the development of electrical potentials, it has been suggested that electrical stimulation increases healing only indirectly, through induced inflammation $(9,14,29,41)$. Electrical stimulation may produce inflammation because of the electrolysis that occurs at the electrode-tissue interface. Similarly, Spadaro $(29,41)$ suggested that an added stressor (or induced mechanical deformation) was required in order for direct stimulation to accentuate bone development. The outside force needed might merely be the insertion of the electrode into the bone, electrode motion, or the original traumatizing injury itself. However, at least pertaining to the injury itself acting as a stressor, the lack of responsiveness of "fresh" fractures to DC stimulation $(19,26,42)$ reduces the plausibility of the stressor hypothesis.

Extremely low frequency (ELF) EMF, has been shown to directly boost DNA synthesis (43), transcription (44), and protein synthesis (44). These effects seem to be mediated by alterations in membrane receptor conformation, $\mathrm{Ca}^{2+}$ channels located in the cell membranes, or second messenger systems in collagen-producing osteoblasts or related cells (20,31). Further ELF EMF has been shown to desensitize parathyroid hormone (PTH) receptors (45) and increase the number of growth factor hormone receptors (e.g., IGF-II) $(31,42,46)$.

Goodman et al (20) suggested that the most reasonable hypothesis explaining activation of cells by ELF EMF relates to changes in conformation of cell membrane receptors, including $\mathrm{Ca}^{2+}$ channels, which eventually activate second messenger systems leading to increased intracellular activity and growth. EMF also affects cAMP levels, protein kinsases, and other calcium dependent processes almost certainly through post-receptor events (9). Based upon these studies, collagen formation would likely be a product of increased cell activity (by activation of receptors and second messenger systems, which in turn act on protein synthesis). However, no direct evidence for such increased cell activity has been completely demonstrated.

Other studies have suggested that the elevation in healing may be partially due to angiogenesis (especially if there is 
increased heat production at the treatment site) $(11,12,39)$. Capacitive coupling stimulation has also been shown to alter cAMP levels, but the significance of this is not known (9). At a molecular level, it has been proposed that elevated DNA replication, accelerated protein synthesis (including collagen), and ultimately activation of cell growth are associated with electrically induced transmembrane currents $(43,47,48)$.

Many of the mechanisms discussed above for hard tissue have also been suggested as possible explanations for utilizing electrotherapeutics to accentuate the healing of skin lesions. However, several other modes have also been proposed that pertain more directly to skin healing. For instance, studies have reported that fibroblasts can be electrically stimulated to enter the cell cycle (DNA replication) in response to EMF fields $(32,34,49,50)$. Sheffet et al (5) proposed that electrotherapeutics may generate heat and/ or magnetic fields within soft tissue, thereby leading to some initial cell activation steps and therein induce healing. Neoangiogenesis $(11,12,39)$ or increased local circulation $(8,51)$ also seems to be a factor in the initiation of the therapeutic effects resulting from electrical stimulation of skin because a continuous supply of oxygen is essential for the growth of cells and therefore collagen production. Finally, because voltage gated calcium channels have been isolated in human and mouse fibroblasts (8), it remains possible that this particular receptor/channel has an important role in electrotherapeutics applications for soft tissues.

\section{TREATMENT}

\section{Bone}

Electrotherapeutics are used clinically to treat a variety of orthopedic injuries or disorders including non-union and stress fractures, pseudoarthroses, spinal fusions, and avascular necrosis of the femoral head $(52,53)$. These clinical treatments are based on the link between stress in living bone, measurable electric potentials and bone growth at the cathode pole. Further, Friedenberg et al (54) found that in areas of active bone growth/repair (and therefore collagen formation) an electronegative potential existed.

Guzelsu et al (55) related this electrical activity within bone to the movement of electrolytes within small channels in bone. It is noteworthy that, although these currents provide the underlying basis for utilizing electrotherapeutics in bone, there is still no conclusive proof that these currents are necessary for the healing process (29).

In accordance with the electronegativity of bone repair sites, in continuous DC stimulation the cathode is typically placed at the site of interest $(6,18,19)$. Asymmetric-waveform AC (biphasic stimulation) appears to correspond better than DC stimulation to the endogenous potentials in bone (i.e., mimics natural currents), and also has been found to stimulate bone formation at the injury site $(3,6)$. Whether using AC or DC current, a significant amount of osteogenesis (i.e., collagen deposition) occurs when a current range between 5 and 20 microamperes is used $(6,56)$. Values above this range have produced varied effects including necrosis and/or tissue destruction whereas values below this range are ineffective.

There are a limited number of studies pertaining to the use of capacitive coupling for bone repair, with a few reporting positive result $(3,57)$. Pertaining to parameters, Black (3) reported that most of the prior experiments conducted using capacitive coupling stimulation only promoted healing of bone when the internal voltage gradient equaled 0.5 to $1.5 \mathrm{mV} / \mathrm{cm}$. Recently, Benazzo et al (57) reported that capacitive coupling stimulation enhanced bone formation when applied to stress fractures in athletes, but supportive studies have apparently not been conducted.

Most of the electrotherapeutic studies conducted during the last ten years on bone have involved PEMFs or continuous inductive stimulation. Mainly, PEMFs have been used to stimulate the healing of fractures that have failed to respond to other treatments. They have been reported to be $80 \%$ effective in this application $(7,30)$. PEMFs have also been used to accentuate vertebral fusions (52) and stimulate the repair of avascular necrosis of the femoral head (53).

A typical PEMF configuration is described in O'Conner (7) in which stimulation was used to treat non-united fractures of varying degrees and time periods. The PEMFs were generated by elliptical coils that have an output between 10 and 25V. A quasirectangular, asymmetric waveform with 20-22 waveforms each lasting 200 microseconds in bursts of 5 milliseconds was used at $15 \mathrm{~Hz}$. The therapeutically-induced voltage within the tissue was approximately $1.0-1.5 \mathrm{mV} / \mathrm{cm}$, which is very similar to that found to be effective by Bassett et al (30) (i.e., $1.3 \mathrm{mV} /$ $\mathrm{cm})$. Heermeier et al (31) seems to have been successful with continuous EMFs in vitro, but little, if any, evidence exists for these results in vivo. They used a coil that produced a continuous sinusoidal signal at a frequency of $20 \mathrm{~Hz}$ with a maximal induced voltage of $.113 \mathrm{mV} / \mathrm{cm}$ to successfully improve collagen type I mRNA production. Although 
the induced voltages seem to be important in the outcome of EMF treatment, pulse characteristics (35) have been projected as being the most important. For example, pulse amplitude $(7,58)$, frequency $(6,20,58)$, and duration $(58)$ have all been mentioned as essential for an effective clinical outcome. Treatment duration also play a relevant role in whether a positive outcome will occur with respect to non-union fractures. Healing has typically occurred after at least four months of 12 hour/day treatments, but up to one year may be necessary for complete healing to take place in complicated cases (7).

\section{Cartilage}

Similar to bone, articular cartilage responds to a loading force by producing electrical current $(59,60)$. Further, when cartilage is stressed, the electrolytes within the collagen and proteoglycans matrix exit resulting in a residual negative charge (61). Baker et all (17) attempted to experimentally grow hyaline cartilage on rabbit femoral heads stimulated with bimetallic implanted electrodes driven by DC. The experimental group was found to possess more hyaline cartilage (collagen type II) than the control group although both showed evidence of healing, with the control showing more fibrous healing. Some alterations have also been noted in proteoglycan density, articular cartilage thickness, and glycosaminoglycan content in response to PEMFs (18).

Despite these encouraging findings, only Trock et al (21) purposely used electrotherapeutics clinically to enhance cartilage healing. They attempted to determine the effectiveness of PEMFs in the treatment of osteoarthritis of the knee and cervical spine. A single annular coil was used to produce pulsed electromagnetic fields with a coil current of less than 2 amperes at $120 \mathrm{~V}$. The experimental group was treated in a stepwise fashion at $5 \mathrm{~Hz}(10-15$ Gauss), $10 \mathrm{~Hz}$ (1525 Gauss), and $12 \mathrm{~Hz}$ (15-25 Gauss), respectively for $10 \mathrm{~min}-$ utes each. Each treatment lasted 30 minutes with 18 total treatments during the investigation (3-5 per week). The control group was treated the same, except the PEMF generator was never powered during the treatment times. A significant improvement in pain was observed in the experimental group. Although the reasons for improvement are yet to be determined, a hypothesis provided by Trock et al was that the PEMFs caused some growth or repair of the articular cartilage leading to improved absorption of compressive forces and therefore less pain.

Presumably, the pressure-electric current relationship in cartilage offers a treatment option for osteoarthritis and other conditions in which cartilage degeneration is the underlying condition. That electrotherapeutics are not commonly used for these conditions probably reflects the lack of evidence in its efficacy as well as the great variability in types of stimulation. Interestingly, compared to bone, cartilage can be more readily stimulated electrically to produce a measurable mechanical stress, similar to that observed in muscle (60). This suggests that cartilage may be more responsive to electrical stimulation than bone and thus further clinical research is warranted.

\section{Tendon \& Ligament}

Electrotherapeutics has been used clinically to treat tendon and ligament damage or sprains for approximately the past 30 years $(13,24,28,33,39,62-68)$. However, few trials have demonstrated efficacy from direct stimulation. Stanish et al (64) reported that tendons and ligaments exposed to a constant $20 \mathrm{~mA}$ current showed greater tensile strength than control groups, but they hypothesized that a foreign body response (i.e., to the electrode) probably played a significant role in the study as some of the tendons showed increased amounts of adhesions. Nessler (13) stimulated rabbit tendon in vitro using a current of $7 \mathrm{~mA}$ leading to potentials ranging between $1.3-1.5 \mathrm{mV} / \mathrm{cm}$. Significant amounts of hydroxyproline, a precursor to collagen fibril units, as well as new collagen fibrils were found in the experimental groups. However, necrosis was also observed at the cathode in these groups. They concluded that appropriate electrode material and placement would have to be determined in order to use this method for healing.

Studies using EMFs to accentuate tendon/ligament healing have had more promising results than those using direct stimulation. Examples include ankle sprains (67), rotator cuff tendonitis (69), and models using rabbit and chicken ligament/tendons $(24,28,33,62,65,66)$. However, Greenough (33), using EMF parameters that had previously been shown to influence new blood vessel growth in rabbits, found no significant increase in the strength of experimentally treated tendons using amplitudes adjusted to produce a peak voltage of $15 \mathrm{mV}$. The induced field was equivalent to $1.5 \mathrm{mV} / \mathrm{cm}$, which was found previously to be effective in bone $(7,30)$. Greenough suggested that the lack of improvement may have been due to the type of waveform used for treatment. Robotti et al(24) suggested that particular waveforms could have a detrimental effect on early tissue healing. Lin et al (62) found that PEMFs promoted the early stages of rabbit ligament healing when exposed to varying field strengths $(2,10$, and 50 Gauss) and, that a dose dependent response was visible in rela- 
tion to field strength and collagen content measured as hydroxyproline levels (28). Their conclusion indicated that when proper intensities were maintained, earlier healing and improved stability following traumatic injuries to ligament or tendon are possible with PEMF stimulation.

\section{Skin}

Currently, treatment of skin wounds (e.g., pressure ulcers, diabetic ulcers, vascular ulcers, traumatic and surgical wounds, grafting/donor sites, skin and tissue flaps, and burns) (4) using electrical stimulation is based on research that revealed that skin has its own "battery," with the surface being negatively charged and the deeper tissues being positively charged (70-73). Becker (74) also described a "current of injury," which related to his finding that intact skin surfaces have a negative charge, but an injured area has a positive charge for a short amount of time ( $<4$ days). Electrical therapy then, similar to its use for orthopedic conditions, is designed to mimic the body's own natural biopotentials and/or add current where presumably insufficient natural current is being produced $(4,12,75)$.

Recent reviews have detailed modality, waveform, and parameter information considered successful clinically for treating skin lesions with direct stimulation, which has typi- cally been the type used (Table 1) $(4,5)$. Continuous or low-volt direct current (LVDC) has been utilized with and without periodic polarity switching at a current typically between $20-1000 \mathrm{~mA}$ and less than $8 \mathrm{~V}$. Usually the anode or cathode (there is not a consensus as to which provides better results) is soaked in saline and placed in the wound, which is stimulated 2-4 hours/day for 3-7 days per week. However, Canseven et al (75) deviated from the ranges provided by Lampe (4) and Shaffer et al (5), utilizing a LVDC regimen of $8 \mathrm{hrs} /$ day. They too reported a notably efficacious outcome without deleterious effects.

High-voltage pulsed direct current (HVPC) or pulsed direct current (PDC) are more commonly used for skin lesions than is LVDC $(4,5)$. Polarity switching is often used in these therapies as well, with the cathode primarily acting to stimulate granulation tissue. Currents for HVPC/ PDC range between $300 \mathrm{~mA}-2.5 \mathrm{~mA}$ at voltages of 6-200V. Pulse rate is classically between 80 and 130 pulses/second. Treatment times are short (60 minutes/day, 5 days/ week) in comparison to LVDC.

Pulsed microamperage direct current (PMDC), most commonly from a TENS unit, has been successfully used to treat skin lesions. Current ranges between 15 and $30 \mathrm{~mA}$ at pulse rates between 64 and 128 pulses/second are typical.

Table 1. Comparison of types of stimulation and typical parameter settings for treatment of skin wounds

\begin{tabular}{|c|c|c|c|c|c|c|c|}
\hline Type & Waveform & Frequency & Current range & Voltage & Polarity & Duration & Other \\
\hline $\begin{array}{l}\text { Low Voltage } \\
\text { DC }\end{array}$ & $\begin{array}{l}\text { Monophasic } \\
\text { Rectangular }\end{array}$ & NA & $20-1000 \mathrm{~mA}$ & $<8$ & $\begin{array}{l}\text { Periodic } \\
\text { switching } \\
\text { (cathode } \\
\text { in wound } \\
\text { for first 3- } \\
5 \text { days) }\end{array}$ & $\begin{array}{l}\text { 2-8hrs/day } \\
\text { for } 3-7 \\
\text { days/week }\end{array}$ & \\
\hline $\begin{array}{l}\text { High Voltage } \\
\text { DC or Pulsed } \\
\text { DC }\end{array}$ & Monophasic & 80-130 pps & $300 \mathrm{~mA}-2.5 \mathrm{~mA}$ & $6-200$ & $\begin{array}{l}\text { Periodic } \\
\text { switching }\end{array}$ & $\begin{array}{l}60 \mathrm{~min} / \text { day for } \\
5 \text { days/week }\end{array}$ & \\
\hline $\begin{array}{l}\text { Pulsed Micro- } \\
\text { ampere DC } \\
\text { (TENS unit) }\end{array}$ & Monophasic & 64-128pps & $15-30 \mathrm{~mA}$ & 9 & $\begin{array}{l}\text { Switch } \\
\text { every } 3 \\
\text { days }\end{array}$ & $\begin{array}{l}30-45 \mathrm{~min}, \\
3 \mathrm{X} \text { daily }\end{array}$ & $\begin{array}{l}\text { Electrodes placed } \\
\text { in web spaces of } \\
\text { hands for lower } \\
\text { extremity ulcers }\end{array}$ \\
\hline $\begin{array}{l}\text { Low Voltage } \\
\mathrm{AC}\end{array}$ & $\begin{array}{l}\text { Symmetrical } \\
\text { Biphasic }\end{array}$ & 40-85 pps & $15-25 \mathrm{~mA}$ & $<10$ & NA & $2 \mathrm{hrs} / \mathrm{day}$ & $\begin{array}{l}\text { Electrodes at edge } \\
\text { of wound }\end{array}$ \\
\hline $\begin{array}{l}\text { Pulsed Electro- } \\
\text { magnetic Fields }\end{array}$ & Biphasic & $8-600 \mathrm{~Hz}$ & $\begin{array}{l}750 \mathrm{~mA} \\
\text { (Coil current) }\end{array}$ & $\begin{array}{l}120 \text { (Coil } \\
\text { voltage) }\end{array}$ & NA & $\begin{array}{l}30 \mathrm{~min} / \text { day, } \\
2 \mathrm{X} \text { daily }\end{array}$ & $\begin{array}{l}\text { No contact with } \\
\text { wound }\end{array}$ \\
\hline
\end{tabular}

Data adapted and modified from references $4,5,75$

$\mathrm{NA}=$ not applicable 
Treatment usually consists of 30-45 minute sessions, 3 times/day with electrode placement some distance from the site of injury (Table 1) (4). Lastly, low voltage ( $<10 \mathrm{~V})$ alternating current (LVAC) with a low frequency (40-85 pulses/second) waveform can be used to treat skin injuries (5). The current ranges from 15-25mA and are applied therapeutically for two hours daily with electrode placement near the edge of the wound.

In addition to treatment duration (i.e., minutes/day), the timing of the onset of treatment has been varied in different treatment regimens. Because fibroblasts do not begin to appear until at least 3 days post-injury, Canseven et al (75) and Enwemeka et al (39) suggested application of electrotherapeutics should be delayed until 3-5 days after injury. This delay also partially coincides with the reversal of injury potential in 3-4 days (74) and the onset of collagen production on day 7 post-injury (39). Pulse duration, when applicable, have also been projected as key to providing an efficacious result in wound healing. Biedebach (8) reported in a review paper that successful durations were most often between $50 \mathrm{~ms}$ and $3.1 \mathrm{~ms}$.

Capacitive coupling has apparently not been utilized to treat skin injuries but Sheffet et al (5) compiled information pertaining to PEMFs and their specific usage in pressure ulcer healing (Table 1). A frequency range of 80$600 \mathrm{~Hz}$ with a pulse duration of 65 pulse per second was found to be successful. Treatment included two applications daily for 30 minutes until the wound healed. The non-invasiveness of EMFs is an obvious benefit in treating wounds. The external coils can be applied without touching the wound or dressing, removing a major risk of infection and potential complications.

\section{CONCLUSIONS}

There is substantial evidence supporting the use of electrotherapeutics in bone healing. O'Connor (7) and Bassett (25) have identified specific orthopedic problems that have been most likely to benefit from electrotherapeutics, in particular PEMF, although DC current has been and can be used as well $(3,9,56)$. Ununited fractures, delayed unions, nonunions, failed arthrodesis, and congenital nonunions are all considered to be responsive to PEMF. The parameter best identified with success in PEMF has been the induced voltages. It has been suggested by Black (3) that an induced voltage of between 1 and $10 \mathrm{mV} / \mathrm{cm}$ be used in bone, whereas O'Connor (7) had suggested a more limited range $(1.0-1.5 \mathrm{mv} / \mathrm{cm})$. The frequency suggested by O'Connor (7) and Bassett (35) to be most effective for nonunion fractures is $15 \mathrm{~Hz}$.

Continuous DC current has been used with success in nonunions when amperage has ranged between the 5 and $20 \mathrm{~mA}(6,56)$. It seems however that the use of DC current, of any type, in bone healing has decreased due to the non-invasiveness and ease of use of PEMF.

Table 1 presents some guidelines for the treatment of skin. Unfortunately, the variability in the listed parameters is very large with no clear consensus relating specific parameters or types of stimulation with specific patients or lesions.

The treatment of other tissues including ligaments, tendons, and cartilage with electrotherapeutics has promise, but it remains to be discovered which specific injuries or lesions are most responsive to electrotherapeutics.

Electrotherapeutics clearly can have a positive effect on collagen healing in calcified and soft tissues. Nevertheless, the precise mechanism of action remains elusive, preventing clear guidelines and parameters for its usage from being codified. However, because there are now at least parameter ranges within which no significant deleterious effects have been reported, physicians should be willing to use electrotherapeutics in cases in which more standard therapy has not produced positive results.

\section{ACKNOWLEDGEMENTS}

We are very grateful to Dr. John C. King for his many helpful suggestions for improving this manuscript. One of the authors (MS) was supported by the Summer Research Program of the Indiana University School of Medicine-Fort Wayne while researching this topic. We thank Mrs. Linda Adams for providing assistance with typing and organizing the references.

\section{REFERENCES}

1. Yasuda I, Noguchi K, Sata T. Dynamic callus and electric callus. J Bone Joint Surg 1955;37(A):1292.

2. Fukada E, Yasuda I. On the piezoelectric effect of bone. J Phys Soc Japan 1957; 12:1158-1162.

3. Black J. Tissue response to exogenous electromagnetic signals. Orthop Clinics N Am 1984;15:15-31.

4. Lampe KE. Electrotherapy in tissue repair. J Hand Ther 1998;11:131-139.

5. Sheffet A, Cytryn AS, Louria DB. Applying electric and electromagnetic energy as adjuvant treatment for pressure ulcer: A critical review. Ostomy/Wound 
Management 2000;46:28-44.

6. Herbst E. Electric stimulation of bone growth and repair: a review of the different stimulation methods. In: Burny F, Herbst E, Hinsenkamp M, eds. Electric Stimulation of Bone Growth and Repair. Berlin: Springer-Verlag, 1978:1-13.

7. O'Connor BT. Treatment of surgically resistant nonunions with pulsed electromagnetic fields. Recontr Surg Traumat 1985;19:123-132.

8. Biedebach MC. Accelerated healing of skin ulcers by electrical stimulation and the intracellular physiological mechanisms involved. Acupuncture Electro-Ther Res Int J 1989; 14:43-60.

9. Slade JF, Chou KH. Bony tissue repair. J Hand Ther 1998;11:118-124.

10. Shannon RV. A model of safe levels for electrical stimulation. IEEE Trans Biomed Eng 1992;39:424426.

11. Reger SI, Hyodo A, Negami S et al. Experimental wound healing with electrical stimulation. Artificial Organs 1999;23:460-462.

12. Reed BV. Peripheral vascular effects of electrical stimulation. In: Currier DP, Nelson RM, eds. Dynamics of Human Biologic Tissues. Philadelphia: FA Davis, 1992:134-162.

13. Nessler JP, Mass DP. Direct-current electrical stimulation of tendon healing in vitro. Clin Orthop 1987;217:303-312.

14. Becker RO. Electrical osteogenesis - pro and con. Calcif Tiss Res 1978;26:93-97.

15. Spadaro JA. Electrically stimulated bone growth in animals and man. Review of the literature. Clin Orthop 1977; 122:325-332.

16. Spadaro JA. Electrical osteogenesis-Role of the electrode material. In: Brighton CT, Black J, and Pollack S, eds. Electrical Properties of Bone and Cartilage. New York: Grune and Stratton, 1979:189-198.

17. Baker B, Becker RO. A study of electrochemical enhancement of articular cartilage repair. Clin Orthop 1974; 102:251-267.

18. Threlkeld AJ. Electrical stimulation of articular cartilage. In: Currier DP, Nelson RM, eds. Dynamics of Human Biologic Tissues. Philadelphia: FA Davis, 1992:255-270.

19. Einhorn TA. Current concepts review. Enhancement of fracture-healing. J Bone Joint Surg 1995;77(A):940956.

20. Goodman R, Shirley-Henderson A. Effects of electric and magnetic fields on transcription. In: Carpenter DO, Ayrapetyan S, eds. Biological Effects of Electric and Magnetic Fields. Volume 2. San Diego: Academic Press, 1994:155-176.

21. Trock DH, Bollet AJ, Markoll R. The effect of pulsed electromagnetic fields in the treatment of osteoarthritis of the knee and cervical spine. Report of randomized, double blind, placebo controlled trials. J
Rheumatol 1994;21:1903-1911.

22. Macklis RM. Magnetic healing, quackery, and the debate about health effects of electromagnetic fields. Ann Intern Med 1993;118:376-383.

23. Stuchly MA. Applications of time-varying magnetic fields in medicine. Crit Rev Biomed Eng 1990;18:89124.

24. Robotti E, Zimbler AG, Kenna D, et al. The effect of pulsed electromagnetic fields on flexor tendons in chickens. J Hand Surg [Br] 1999;24:56-58

25. Bassett CAL. The development and application of pulsed electromagnetic fields (PEMFs) for ununited fractures and arthrodeses. Clinics Plast Surg 1985;12:259-277.

26. Norton LA. Pulsed electromagnetic field effects on chondroblast culture. Recontr Surg Traumat 1985;19:70-86.

27. Zimmermann KP, Simpson RK. "Slinky" coils for neuromagnetic stimulation. Electroenceph Clin Neurophysiol 1996;101:145-152.

28. Lin Y, Nishimura R, Nozaki K et al. Kadosawa T, Goto N, Date M, Takeuchi A. Collagen production and maturation at the experimental ligament defect stimulated by pulsing electromagnetic fields in rabbits. J Vet Med Sci 1993; 55:527-531.

29. Spadaro JA. Mechanical and electrical interactions in bone remodeling. Bioelectromagnetics 1997;18:193202.

30. Bassett CAL, Pawluk RJ, Pilla AA. Acceleration of fracture repair by electromagnetic fields. A surgically non-invasive method. Ann NY Acad Sci 1974;238:242-262.

31. Heermeier K, Spanner M, Trager J et al. Kraus W, Schmidt J. Effects of extremely low frequency electromagnetic field (EMF) on collagen type I mRNA expression and the extracellular matrix synthesis of human osteoblastic cells. Bioelectromagnetics 1998;19:222-231.

32. Schimmelpfeng J, Dertinger H. Action of a $50 \mathrm{~Hz}$ magnetic field on proliferation of cells in culture. Bioelectromagnetics 1997;18:177-183.

33. Greenough CG. The effect of pulsed electromagnetic fields on flexor tendon healing in rabbit. J Hand Surg [Br] 1996;21:808-812.

34. Ross SM. Combined DC and ELF magnetic fields can alter cell proliferation. Bioelectromagnetics 1990;11:27-36.

35. Bassett CAL. Therapeutic uses of electric and magnetic fields in orthopedics. In: Carpenter DO, Ayrapetyan S, eds. Biological Effects of Electric and Magnetic Fields. Volume 2. San Diego: Academic Press, 1994:13-48.

36. MacLeod KJ, DonahueHJ, Levin PE, et al. Electric fields modulate bone cell function in a density-dependent manner. J Bone Miner Res 1993;8:977-984.

37. Takahashi K, Kaneko I, Date M, et al. Effect of puls- 
ing electromagnetic fields on DNA synthesis in mammalian cells in culture. Experientia 1986;42:185-186.

38. Bassett CAL. Fundamental and practical aspects of therapeutic uses of pulsed electromagnetic fields (PEMFs). CRC Crit Rev Biomed Eng 1989;17:451529.

39. Enwemeka SC, Spielholtz NI. Modulation of tendon growth and regeneration by electrical fields and currents. In Currier DP, Nelson RM eds. Dynamics of Human Biologic Tissues. Philadelphia: FA Davis, 1992:231-254.

40. Loeb GE, Zamin CJ, Schulman JH et al. Injectable microstimulator for functional electrical stimulation. Med Biol Eng Comput 1991;29:NS13-9.

41. Spadaro JA, Albanese SA, Chase SE. Bone formation near direct current electrodes with and without motion. J Orthop Res 1992;10:729-738.

42. Baggs AC. Portable bone-growth stimulators go domestic in USA. Lancet 1996;347:1474.

43. Liboff AR, Williams T, Strong DM et al. Time-varying magnetic fields: effect on DNA synthesis. Science 1984;223:818-820.

44. Goodman R, Wei L, Xu J et al. Exposure of human cells to low-frequency electromagnetic fields results in quantitative changes in transcripts. Biochim Biophys Acta 1989;1009:216-220.

45. Luben RA. In Vitro systems for the study of electromagnetic effects on bone and connective tissue. In: Carpenter DO, Ayrapetyan S, eds. Biological Effects of Electric and Magnetic Fields. Volume 2. Academic Press, San Diego, CA 1994:103-119.

46. Fitzsimmons R, Ryaby J, Magee F et al. IGF II receptor number is increased in TE-85 osteosarcoma cells by combined magnetic fields. J Bone Miner Res 1995;10:812-819.

47. Cridland NA, Cragg TA, Haylock RGE et al. Effects of $50 \mathrm{~Hz}$ magnetic field exposure on the rate of DNA synthesis by normal human fibroblasts. Int J Radiat Biol 1996;69:503-511.

48. Shteyer A, Norton LA, Rodan GA. Electromagnetically induced DNA synthesis in calveria cells. J Dent Res 1980;59:362.

49. Cheng K, Goldman RJ. Electric fields and proliferation in a dermal wound model: cell cycle kinetics. Bioelectromagnetics 1998;19:68-74.

50. Bourguignon GJ, Bourguignon LYW. Electric stimulation of protein and DNA synthesis in human fibroblasts. FASEB J 1987;1:398-402.

51. Omura Y. Pathophysiology of acupuncture: effects of acupuncture on cardiovascular and nervous systems. Acupuncture Electro-Ther Res Int J 1975;1:51-141.

52. Hotta SS. Electrical bone-growth stimulation and spinal fusion. Health Technology Review. US Dept of Health and Human Services, Office of Health Technology Assessment, Agency for Health Care Policy and Research of the Public Health Service, January
1994;8:1-6.

53. Mont MA, Hunferford DS. Current concepts review. Non-traumatic avascular necrosis of the femoral head. J Bone Joint Surg 1995;77(A):459-474.

54. Friedenberg ZB, Brighton CT. Bioelectric potentials in bone. J Bone Joint Surg 1966;48(A):915-923.

55. Guzelsu N, Walsh WR. Streaming potentials in intact wet bone. J Biomech 1990; 23:673-685.

56. Steiner M, Ramp WK. Electrical stimulation of bone and its implications for endosseous implantation. J Oral Implant 1990;16:20-27.

57. Benazzo F, Mosconi M, Beccarisi G, et al. Use of capacitive coupled electric fields in stress fractures in athletes. Clin Orthop 1995;310:145-149.

58. Cané V, Botti P, Soana S. Pulsed magnetic fields improve osteoblast activity during the repair of an experimental osseous defect. J Orthop Res 1993;11:664670 .

59. Bassett CAL, Pawluk RJ. Electrical behavior of cartilage during loading. Science 1972;178:982-983.

60. Lotke PA, Black J, Richardson S. Electromechanical properties in human articular cartilage. J Bone Joint Surg 1974;56:1040-1046.

61. Frank EH, Grodzinsky AJ. Cartilage biomechanics. I. Electrokinetic transduction and the effects of electrolyte $\mathrm{pH}$ and ionic strength. J Biomech 1987;20:615627.

62. Lin Y, Nishimura R, Nozaki KK, et al. Effects of electromagnetic fields on ligament healing in rabbits. $\mathrm{J}$ Vet Med Sci 1992;54:1017-1022.

63. Akai M, Oda H, Shirasaki Y et al. Electrical stimulation of ligament healing. Clin Orthop 1988;235:296301.

64. Stanish WD, Rubinovich M, Kozey J et al. The use of electricity in ligament and tendon repair. Physician Sportsmed 1985;13:109-116.

65. Frank C, Amiel D, Schachar M, et al. The electromagnetic stimulation of ligament healing in a rabbit model-collagen analysis by gel electrophoresis. Orthop Trans 1981;5:474-475.

66. Frank C, Schachar N, Dittrich D, et al. Electromagnetic stimulation of ligament healing in rabbits. Clin Orthop 1983; 175:263-272.

67. Wilson DH. Treatment of soft-tissue injuries by pulsed electrical energy. BMJ 1972;2:269-270.

68. Owoeye I, Spielholtz NI, Fetto J, et al. Low intensity pulsed galvanic current and the healing of rat Achilles tenotomized tendons: Preliminary report using loadto-breaking measurements. Arch Phys Med Rehabil. 1987;68:415-418.

69. Binder A, Parr G, Hasleman B et al. Pulsed electromagnetic field therapy of persistent rotator cuff tendonitis. Lancet 1984;1:695-698.

70. Burr HS, Harvey SC, Taffel M. Bio-electric correlates of wound healing. Yale J Biol Med 1938-39;11:103107. 
71. Jaffe LF, Vanable JW. Electric fields and wound healing. Clin Dermatol 1984;3:34.

72. Foulds IS, Barker AT. Human skin battery potentials and their possible role in wound healing. Br J Dermatol 1983;109:515-2273.

73. Barker AT, Jaffe LF, Vanable JW. The glabrous epidermis of cavies contains a powerful battery. J Physiol
(Lond) 1982;11:R248.

74. Becker RO. The Body Electric. Los Angeles: William Morrow, 1985.

75. Canseven AG, Atalay NS. Is it possible to trigger collagen synthesis by electric current in skin wounds? Ind $J$ Biochem Biophysics 1996;33:223-227. 